\title{
Italian research on eco-efficient housing modules
}

\author{
F. Gugliermetti ${ }^{1} \&$ R. Roversi ${ }^{2}$ \\ ${ }^{1}$ CITERA Territory Construction Restoration Interdepartmental Centre, \\ Sapienza University of Rome, Italy \\ ${ }^{2}$ DIAEE Dipartimento di Ingegneria Astronautica, Elettrica ed \\ Energetica, Sapienza, University of Rome, Italy
}

\begin{abstract}
The theme of eco-efficient houses is now highly topical in Italy. Universities and companies specialized in sustainable construction are developing projects of experimental buildings that may constitute a typological and constructive reference and may offer the opportunity to monitor their physical and technical performance in order to check the expected theoretical results, environmental quality and energy efficiency. To focus on which are the main fields of research in Italy and assess their progress, it may be useful to carry out a survey and a comparison between the main development experiences related to the topic of experimental modules and prototypes. The paper analyses and highlights the common features of the last and more significant Italian examples. It also describes technological solutions, materials and energy strategies used in the analyzed experimental buildings, and finally focuses on the main future developments that are involved in Italian research and experimentations on ecoefficient housing units.

Keywords: energy-efficient architecture, eco-efficient housing units, experimental buildings, housing modules, prefabricated buildings, housing prototypes, environmental sustainability.
\end{abstract}

\section{Introduction}

The subject of an eco-efficient, ecological or sustainable dwelling, upon which both the community of research and the construction industry have put a lot of focus, is now a topical issue in Italy, also due to the pressure of European energy 
policies, which have long been promoting the development of low-energy buildings. With the Law $\mathrm{n}^{\circ} 90$ of 03/08/2013, Italy adopted the European Directive 2010/31/EU, which introduces the concept of a Near Zero Energy Building (NZEB). It is defined as a "building with a very high energy performance" in which "the nearly zero or very low amount of energy required should to a very significant extent be covered by energy from renewable source" [1]. Furthermore, in Italy, new assessing criteria and certifications of constructions that are sustainable in terms of energy and environment are established, and promoted as well by the Regions, in support of their local policies [2]. Some groups of Italian universities, designers, and companies specialized in sustainable building, are developing prototypes of small housing units conceived as a typological and architectural reference for the future houses. The prototypes are modules intended for housing or for the service industry, supplied with all the equipment necessary to be fully functional. These modules are useful not only for design experimentation, but also to assess the interaction between different components, related to both structure and plant, in order to develop integrated systems, select the products available on the market and encourage their improvement, while promoting exchange and synergy between different manufacturing sectors. Moreover, they offer the opportunity to monitor the physical and technical performance of the architectural organism, in order to verify its conformity with the expected theoretical results, and to determine its environmental quality and energy efficiency in operation.

\section{Italian eco-efficient experimental prototypes}

In 2006, Edilportale, an Italian web portal providing technical information for the building industry, in association with the Building Environment Science \& Technology Department of Polytechnic of Milan, has announced the first worldwide design contest for prefabricated modular house projects entitled "Living Box- the house of the future". The successful outcome of the competition has led to many considerations and in-depth analysis on the opportunities offered by the prefabricated units, advanced housing modules that combine features consistent with Near Zero Energy Buildings, with design and with the research on ecological materials and faster and more efficient building technologies.

\subsection{Objectives, main design choices, common features}

A preliminary operational step followed the planning phase, during which the designers presented and displayed the prototype at Smart Village 2013, the convention exhibit on sustainable architecture and energy efficiency in MADE Expo of Milan, in October 2013. The new initiative by Edilportale has gathered around a concept developed by the Department of Civil, Environmental and Mechanical Engineering of University of Trento, several partner companies, who have provided the components for the new Livingbox, a housing unit usable as a temporary accommodation in emergencies or as a permanent solution. They have 
presented Livingbox as a transportable, recyclable and energy efficient prefabricated modular unit. It has obtained the MAKE Sustainable certification, which is issued by ICMQ (Institute of Certification and Quality Brand), an independent certifying body which verifies that the production of components, the managing of the construction site and the distribution of any service comply all with the principles of sustainability [3].

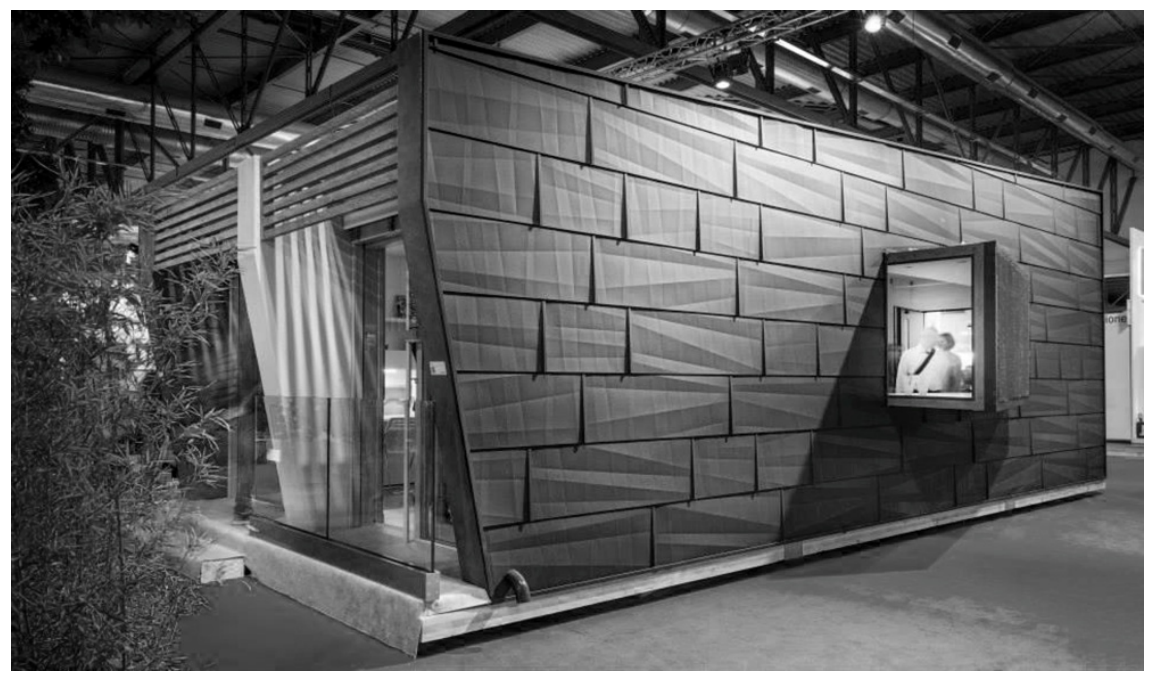

Figure 1: The Livingbox housing prototype exposed in preview at MADE Expo 2013 in Milan. (Courtesy of Prof. Frattari A., Trento University.)

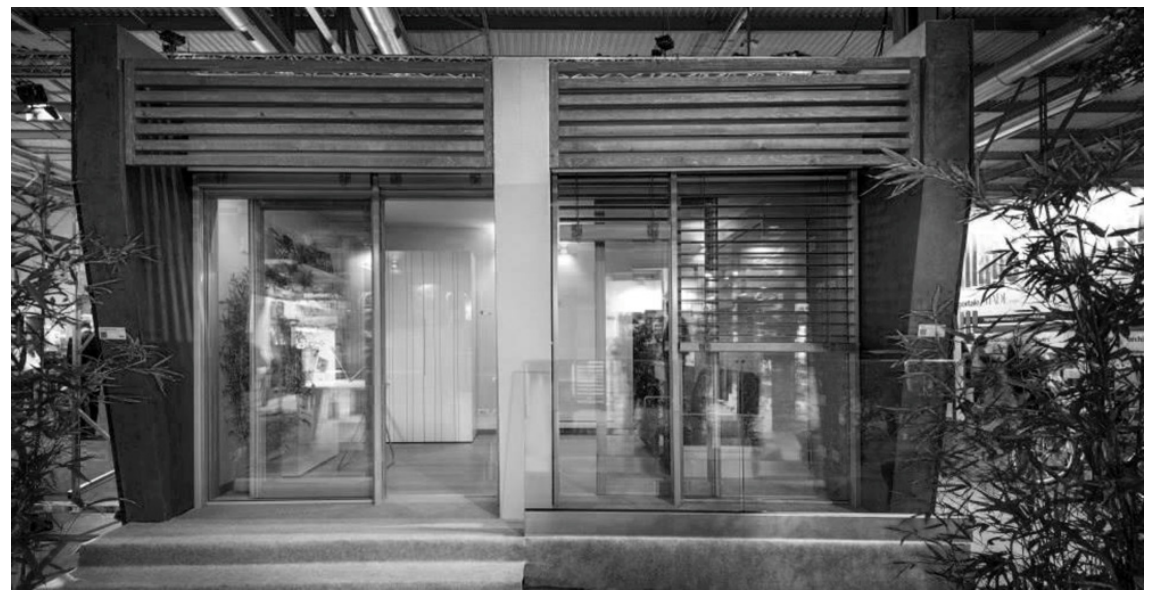

Figure 2: Front of the Livingbox housing prototype, in the version composed by two modules. (Courtesy of Prof. Frattari A., Trento University.) 
The reference solution is a prefabricated modular unit, whose dimensions are comparable to those of a container, thus making it transportable by an 18wheeler. It is possible assembling a single unit or as a combination of more than one unit: the overlapping or the union of more than one modules can generate either a single-family structure of different sizes or several multi-family compounds. The version exhibited at MADE Expo features two combined modules of a total area of 2,5x10 m, made of a kitchen-bathroom unit and a free usable space. The structure is in cross-laminated bearing panels made of spruce (XLAM). A strongly insulated wall, with a very low thermal transmittance composes the shell (figs 1 and 2).

Livingbox represents the strategic choices that are at the base of most of the small experimental buildings designed in our country over the last few years. Indeed, the common objectives of all these experiences relate to the following two aspects. Buildings must be modular or composed by a series of variously stackable elements, to have the possibility to combine them in different ways so to create housing units with calibratable dimensions. Besides, they must be flexible, as to allow different scopes and to suit the various needs of consumers. It is also possible to prefabricate them, in order to reduce the time of building up, to guarantee results independent from the characteristics of the building yard. They must be easily transportable; either to guarantee usability as temporary accommodation, in emergency events, or to accommodate residents, whose main house is undergoing renewal. Containing costs is also a very important target. From the point of view of environmental sustainability, the focus is on saving energy, recycling materials and using eco-friendly materials, possibly of natural source (fig. 3).

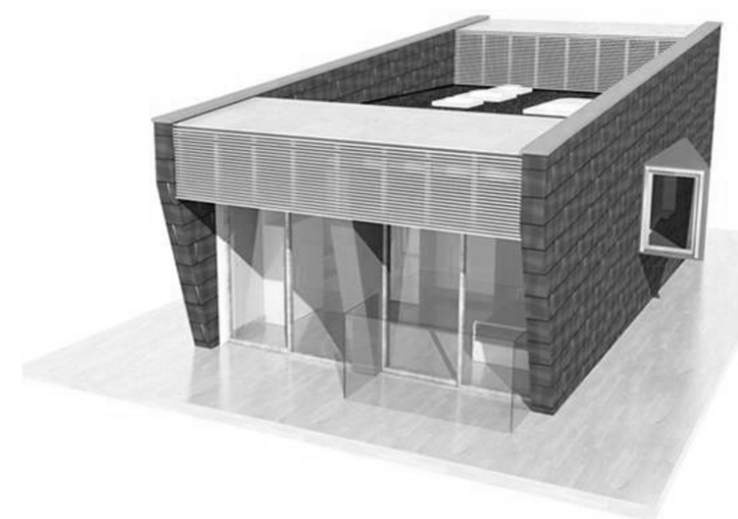

Figure 3: 3D Livingbox housing prototype project. (Courtesy of Prof. Frattari A., Trento University.)

\subsection{Housing modules for the Mediterranean climatic area}

Although prototypes are by their nature regardless of a specific location, they are good to face outdoor conditions typical of the main climatic environment. The 
ecological strategies, such as a correct orientation, the relationship between shape and volume, morphology and type, are therefore designed depending on the geographical zone to which the house is destined [4].

Compared to the passive North European house, designed to face low temperature, the Italian one is adequate to the high summer temperature. A very significant example of the Italian research on this subject is the solar house, which achieved the third place at the 2012 edition of the International Solar Decathlon exhibition [5]. The U.S. Department of Energy created the competition, which is among the most important international events dedicated to green architecture. Through ten contests, the jury examines housing prototypes developed by Universities, monitoring their performance during a period of two weeks. Performances related to temperature, humidity, lighting, soundproofing and operation of equipment are assessed together with energy balance, architectural quality, design for manufacturability, realization costs and the possibility of assembling the prototype in a residential community [6].

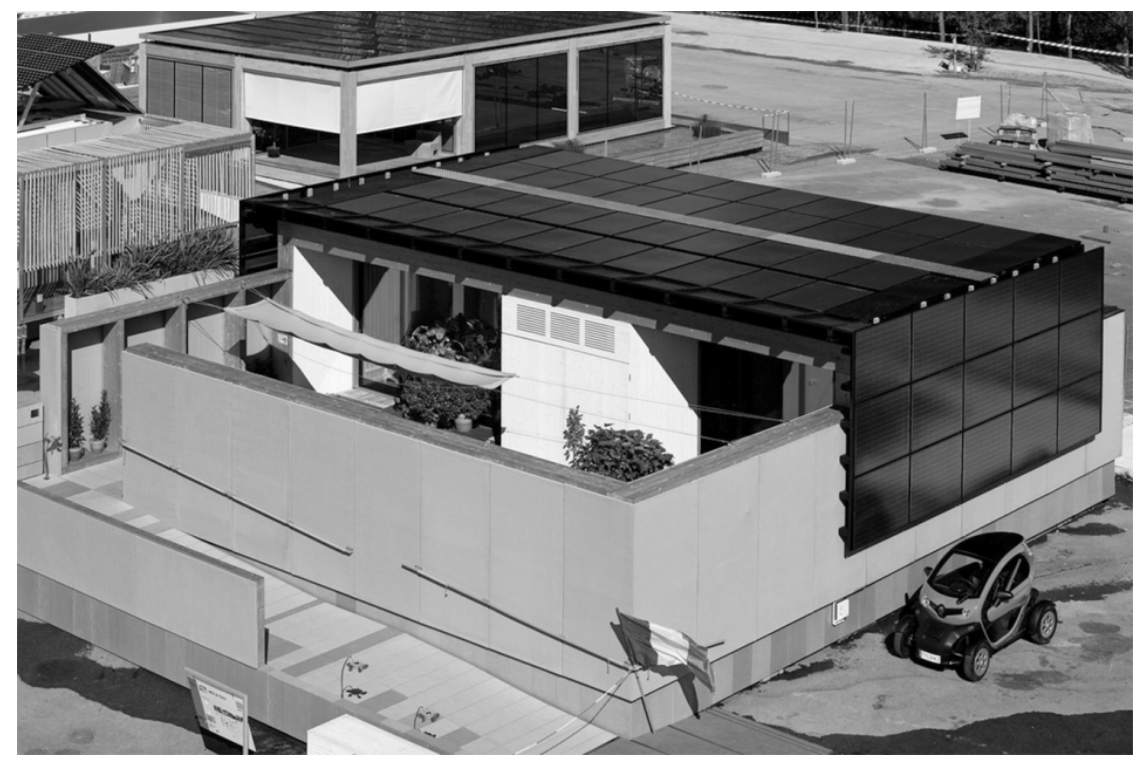

Figure 4: The Med in Italy prototype during the Solar Decathlon Europe international competition in Madrid, 2012. www.sdeurope.org.

The Italian prototype, named Med in Italy, created by teams from Universities of Rome, Sapienza and Roma Tre, is an energetically passive housing module that produces three times the power necessary for it to function, and has achieved the first prize in the Sustainability category. It appears to be an introverted house, where the indoor spaces are around a patio, according to the Mediterranean traditional building (fig. 4). The whole plant design, with standard dimensions and easily transportable, is located in the central nucleus of the house. Some of 
the more appreciated features are the easiness of assembly, the selection of natural materials that can be entirely recycled [7].

The University of Florence in collaboration with Sant'Anna School of Pisa (Tuscany) and several partner companies, by the research project Abitare Mediterraneo, developed another example of design experimentation on housing modules suitable for the Italian climate was developed. The project intends to find sustainable systems and solutions aimed at containing energy consumption through the integration of technological and architectural innovation. The team has developed typological and architectural modules designed for the Mediterranean area, usable either as independent buildings or as extensions of already existent structures. A complete prototype was located in Rispescia, in the province of Grosseto (Tuscany), in a coastal area featuring dunes, which is a disadvantageous area in terms of external mechanical, chemical and thermal solicitations (fig. 5). The prototype, which is completely energy self-sufficient, undergoes monitoring in order to verify the activity of components and technologies, together with the environmental quality and the physical and technical performances [8].

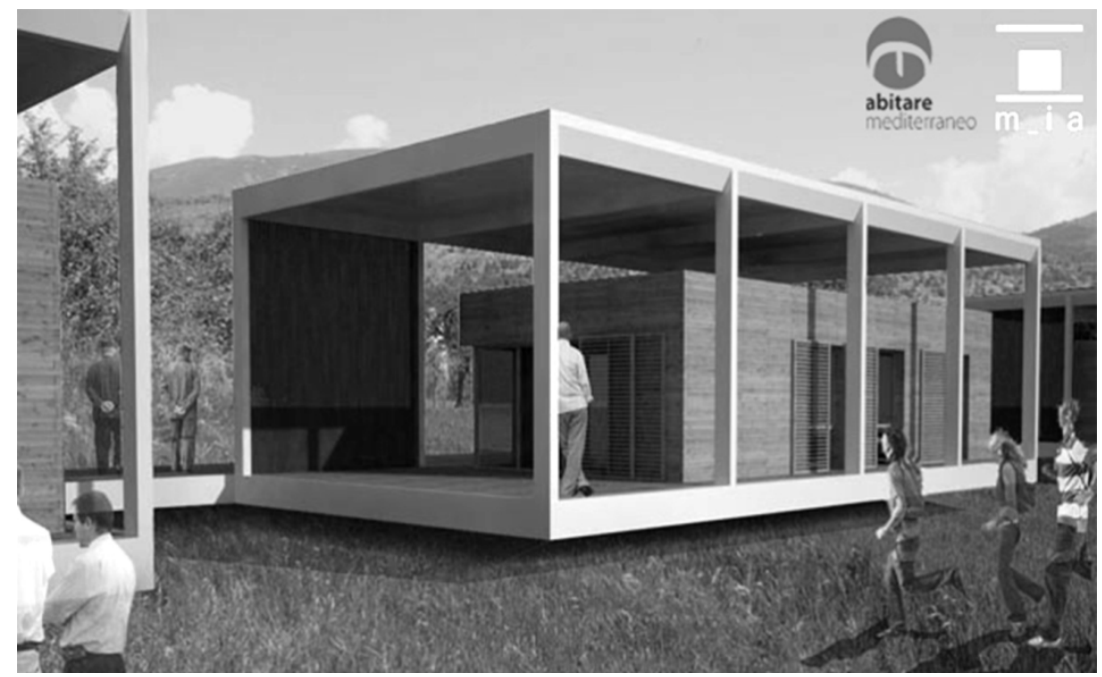

Figure 5: The MIA housing module developed by Abitare Mediterraneo project. www.abitaremediterraneo.org.

Following this trend, we can also mention the research project by CITERA (the Interdepartmental Centre for Territory, Construction, Restoration and Environment) of Sapienza, University of Rome. The project aims to develop prototypes to use for housing or for the service sector that can be located in areas of particular naturalistic value, such as natural reserves. They represent a fragile environmental context that lacks in infrastructures, where interventions should have a low impact on the environment and remain fully reversible. The project, which is still under development, aims to produce a module for the National Park 
of Circeo, placed into a pinewood near sand dunes. Integration between architectural and the plant design was one of the main the focus of the project: a computerized smart metering system controls the module to realize an efficient management of the module (energy consumption, indoor quality, light etc). In addition to that, the possibility of an easy integration between these remote control systems and the latest home automation programs allows the consumers to activate, control and monitor all the functions through any portable device.

The minimal House Diogene, developed by the Renzo Piano Building Workshop at the Vitra Company, exhibited in 2013 at the Art Basel event, differentiates from the other examples as explicitly designed to function regardless of the climatic area. Diogene, clearly influenced by prestigious examples such as the Cabanon by Le Corbusier, measures 2,5x3 meters and has an autonomous energy self-sufficient system. Its structure is made of crosslaminated timber panels, with an aluminum cladding. The reduced dimensions required an accurate study of the space and the internal set-up (fig. 6).

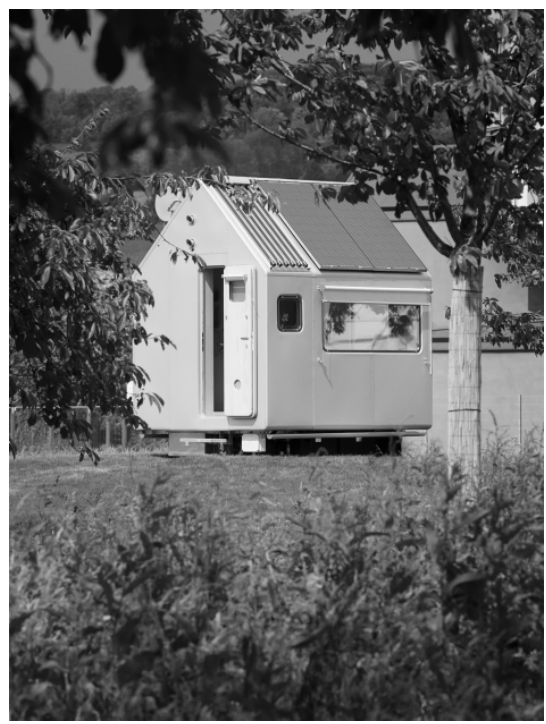

Figure 6: View of Diogene, built in the Vitra campus in Weil am Rhein. Courtesy of (C) Vitra, Ph. Julien Lanoo.

\subsection{Technical solutions and energy supply strategies}

The technological solution and the materials used in the above-mentioned case studies are various, but we can identify some common aspects. The architectural technology employs prefabricated systems that can be pre-assembled in manufacturing or assembled directly on site, always with dry construction. The basic material is usually wood, as it is a natural and high performance material. As far as the other components are concerned, the materials used are usually recycled or recyclable [9]. Insulation solutions showed a wider assortment: for 
instance, just to mention the above-cited examples, the vertical thermal insulation of Livingbox is made of mineral wool panels, while Med in Italy implements the thermal energy storage of the walls using wood wool, and recycled aluminum pipes filled with wet sand. The sustainable house of Abitare Mediterraneo uses kenaf fiber and the CITERA module uses volcanic lapillus, which is typical of the Circeo area. External finish shows multiplicity of materials, according to the environmental context to which the building is destined.

The equipment of energy supply systems using renewable sources, sophisticated plants and technical systems that can guarantee self-sufficiency and independence from the local infrastructures represents a primary aspect, which is common to all the prototypes. Diogene, for instance, draws all the energy needed from solar panels while the rainwater is gathered, filtered and reused (fig. 7).

Livingbox is equipped with a solar greenhouse, intensely using active solar systems, as well as small wind turbines and cogeneration: efficiency and the combination of energy supply systems depend on the geographical location of the module. A monitoring phase will assess energy consumption. Med in Italy draws energy from photovoltaic panels placed as roofing and on the walls that are facing East and West directions, in order to draw solar energy throughout the entire day. The main strategy to adopt in experimental housing units, as well as in all the energetically virtuous buildings, is to limit the thermal waste and maximize the free natural energy supply. Every module has a strongly insulated, airtight shell, the ventilation of spaces occurs naturally, and it is obtained through the strategic positioning of the openings. Moreover, the modules use shading systems to limit the summer overheating [10]. All the Italian prototypes described above are still under development, thus representing experimental apparatus that can undergo future development. For this reason, they are subject to monitoring and we are awaiting data promulgation in order to assess the reliability of project forecasts compared to the activity observed in operation, and possibly carry out suitable changes and corrections.

\section{Conclusions and future developments}

In conclusion, we can assert that the two main sectors in which the Italian scientific research will operate in the near future, in order to develop sustainable and energy efficient prototypes are concerning two opposite scenarios. The first that sees the prototypes as placed in a non-urban area, far from the city, thus allowing a fruition with a low impact on the environment. The second that sees the prototypes placed in areas with a very high urbanization rate. The research carried out by Abitare Mediterraneo and CITERA well represents the first scenario. The new project that the University of Roma Tre team will present next June in France, at the 2014 Solar Decathlon: RhOME for denCity [11] exemplifies the second eventuality. The latter is a sustainable house model conceived to increase residential density in large cities raising the number of accommodation in already built areas, in order to avoid further land consumption (fig. 8). 


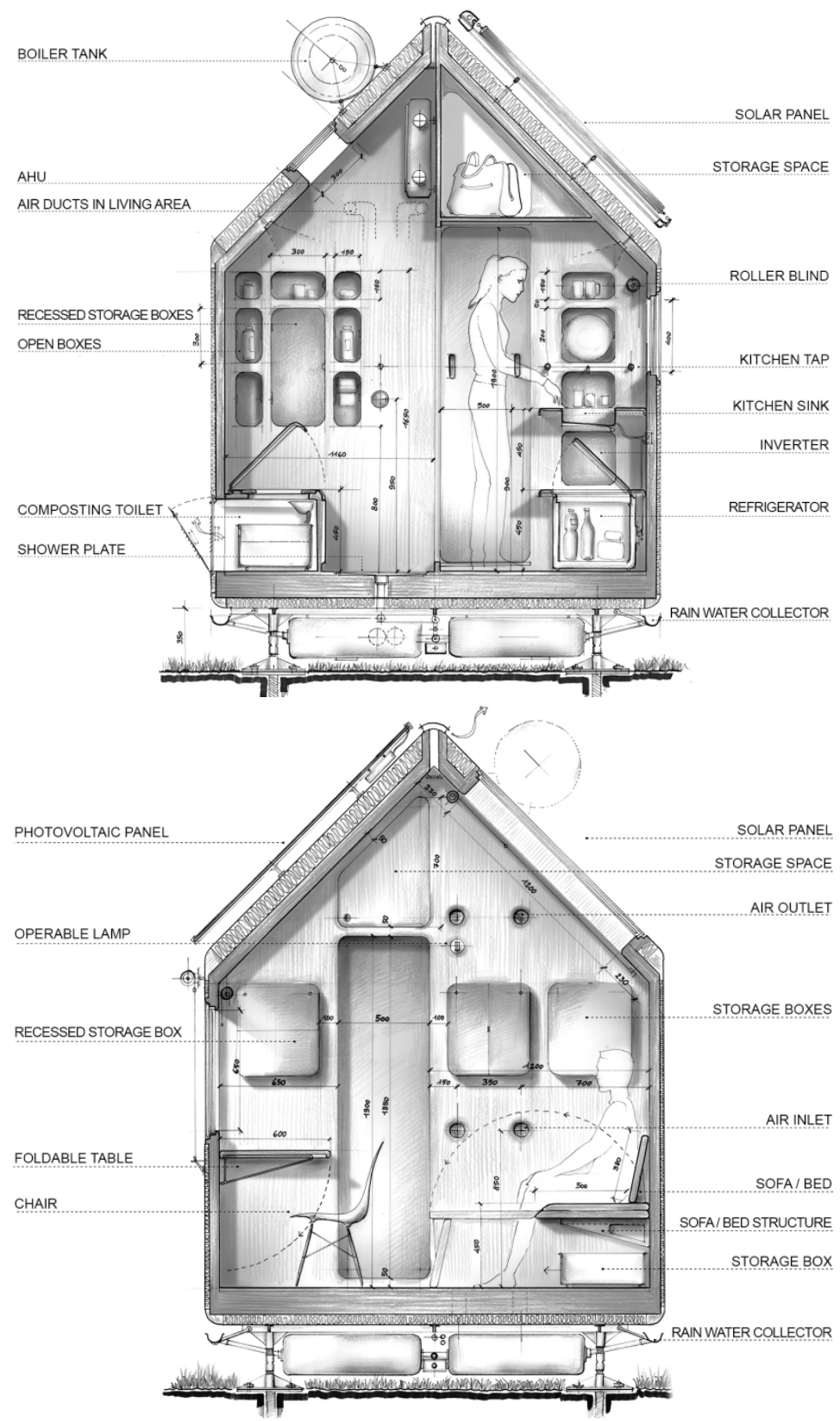

Figure 7: Sections of Diogene, a minimalist, single-occupancy living unit. (Courtesy of Renzo Piano Building Workshop (C RPBW.) 


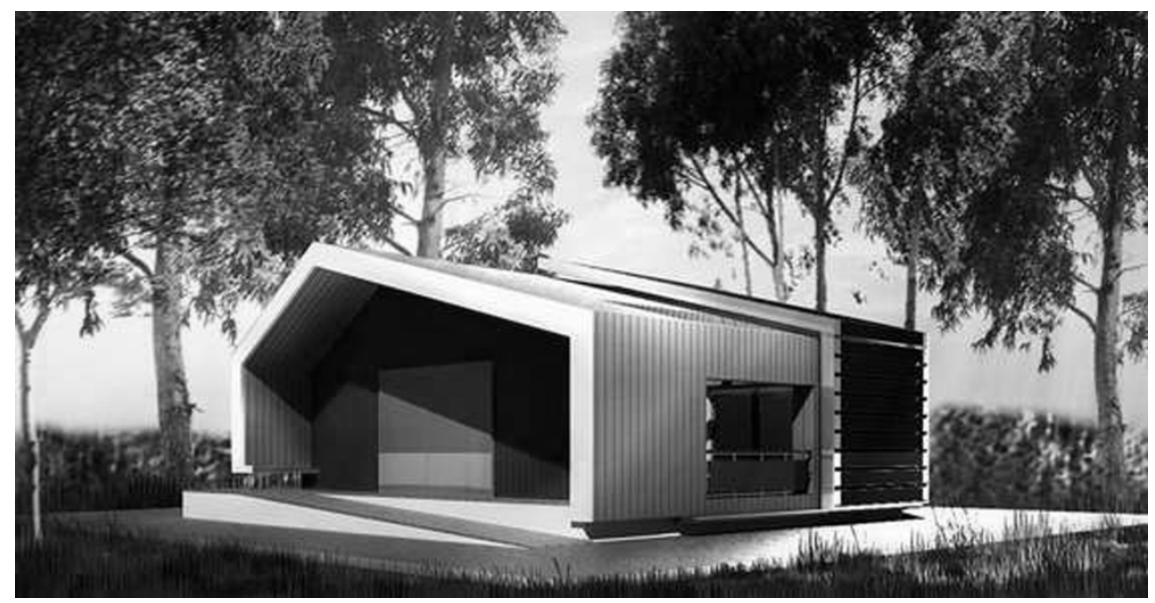

Figure 8: RhOME for denCity, the project that will be presented by Roma Tre University at the next Solar Decathlon 2014. www.rhomefordencity.it

The development of a practical project in Tor Fiscale, a suburban area of the city of Rome, has been included in a neighborhood-scale strategy that adopts the application of "Smart Cities" principles. The design provided a building with a maximum flexibility to meet the needs of a wide variety of consumer categories. The new housing units will have to contribute to the energy supply of the neighborhood where they will be placed, using their energy surplus [12].

The interest of this perspective, concerning the above-mentioned two research fields, lies in the conceiving of the building. It is not only a building featuring important intrinsic innovations, both in terms of energy and environment and in terms of typology and technology, but it is also an active part of the requalification and valorization strategy carried out in the context in which it will be placed. The building itself is no more conceived as a single organism but, through a use that is extended to its different forms, it is now part of a global project investing also in other sectors such as mobility, integration between housing and other functions, the safeguard of the landscape and urban regeneration.

\section{References}

[1] Kurnitski J., Cost Optimal and Nearly Zero-Energy Buildings (Nzeb): Definitions, Calculation Principles and Case Studies, Springer: Berlin, 2013.

[2] Bonanomi M., De Flumeri C., Lavagna M., Edifici a consumo energetico zero. Orientamenti normativi, criteri progettuali ed esempi di zero energy e zero emission buildings, Maggioli Editore: Santarcangelo di Romagna, 2012. 
[3] Living box, prefab living unit, Edilportale, Trento University, www.livingbox.it

[4] Ali S., Sustainability, Energy and Architecture: Case Studies in Realizing Green Buildings, Academic Press/Elsevier: Amsterdam, 2013.

[5] Solar Decathlon, U.S. Department of Energy, www.solardecathlon.gov

[6] Zaretsky M., Precedents in Zero-Energy Design: Architecture and Passive Design in the 2007 Solar Decathlon, Routledge Press: London, 2010.

[7] MED in Italy, the sustainable Mediterranean house, www.medinitaly.eu/it

[8] Abitare Mediterraneo, www.abitaremediterraneo.org, www.regione. toscana.it/-/abitare-mediterraneo, www.dida.unifi.it/vp-215-laboratoriotecnologie-per-l-abitare-mediterraneo.html

[9] Richardson P., XS: Small Structures, Green Architecture, Universe Publishing: New York, 2007.

[10] Boeri A., Longo D., Energy efficiency in buildings in southern Europe: challenges and design strategies, in International Journal of Sustainable Development and Planning, WIT Press: Southampton (UK), vol. 6, pp. 522-526, 2011.

[11] Solar Decathlon Europe 2014, www.solardecathlon2014.fr/en

[12] RhOME for denCity, www.rhomefordencity.it 